DOI https://doi.org/10.18551/rjoas.2017-03.10

\title{
COMPARISON OF GOVERNMENT EXPENDITURE AND SOME REPRESENTATIVE OF AGRICULTURAL PRODUCT PRICES AND THEIR IMPACT ON AGRICULTURAL GROWTH OF PAKISTAN
}

\author{
Kashif Umair, Hong Chen*, Naseem Snovia \\ College of Economics and Management, Northeast Forestry University, Harbin, China \\ *E-mail: nefuchen@126.com
}

\begin{abstract}
This article mainly aims to investigate the link between government expenditure on agriculture, agriculture product prices and performance of agriculture sector in the economy of Pakistan. Time series data collected from World Development Indicators and Food and Agriculture Organization of the United Nations for the period of 1996-2015. The study used Augmented Dickey-Fuller (ADF) unit root test and Autoregressive Distributed Lag (ARDL) approach of co integration to test the relationship between the variables. Results indicate that both government expenditure on agriculture and agriculture product prices are essential to enhancing agriculture growth and there exists long-run relationship between expenditure of government on agriculture, prices of agriculture product and economic growth of Pakistan. Furthermore, agricultural government expenditure is more prominent in effecting the agriculture economic growth with respect to agricultural products prices in the long-run. Therefore, it specifies that government of Pakistan should increase its expenditure and also take initiatives to encourage and motivate the farmers toward increasing productivity by using scarce sources efficiently to bring economic prosperity in the agriculture sector.
\end{abstract}

\section{KEY WORDS}

Agriculture, gross domestic product, expenditure, prices, wheat, rice.

Agriculture is an important sector in the economy of Pakistan and it continuously participates in its rebuilding since independence. This sector led the economy in early time period but due to socio-environmental and political conditions its production yield and overall performance consistently declined. Now, it is the second largest sector with contributing about 20.9 percent in Gross Domestic Product of Pakistan. Approximately, 43.5 percent livelihood of rural population directly or indirectly related to this section (Pakistan bureau of statistics).

Pakistan is an agricultural economy providing employment opportunities to most part of its population; eliminates poverty and contributes towards growth. Presently, the government is completely aware of the role of rural youth in creating administrative division and business enterprises for addition in the value of agriculture. Also its importance to enhance incomes as agribusiness is a key driving force of agriculture associated industries and rural nonfarm economic system. The youth of country is being encouraged in procuring the new abilities for setting agro-based organizations for enhancing household incomes. The areas like livestock, agronomics and fisheries would seek advantage from different programs and schemes of government and this would result in expansion of economic improvement of rural unities and create raw material for our developing foods industries (Pakistan economic survey).

Agriculture sector usually supported an acceptable development to guarantee food safety for our developing population. However, the predominant task faced by now is the low returns to farmers of their items in view of higher expenses of generation (Raza, 2012). This requires well thought intercessions to enhance agriculture commodity cost expansion at the farm tiers and develop modern linkages. Particularly, under the current circumstances when growing expense of generation of agriculture product returns do not equivalent. Comprehension of these difficulties in a vibrant industrial sector may approach ahead to aid the farm section. Presently, focus of concerned authorities are on the expand mechanisms for minimizing production cost to grow the farmer's interest in livestock and farming. As a 
policy, the government is devoted to accommodate appropriate framework support to agroprocessors with the aim to improve esteem expansion and openings for work for developing young population.

Different industrial entities used agriculture and consequential products as raw or processed materials; which comprehensively contribute to the exports of country. It is the largest market for industrial manufactured goods such as pesticides, fertilizers, tractors and agriculture equipment. Although dominance of agriculture has declined eventually due to growing rate of urbanization but still it is a major source of living by most people in rural areas (Altaf, 2009). The object of Agriculture has transformed from "self-reliance" to "Commercialization" and this is called economic operation in Agriculture.

The performance of agriculture sector remained subdued in Pakistan. Essential factors caused by this sluggish performance contains low technological innovation rate, timely input source problem, restricted share in building, maintaining infrastructure and acceptance of progressive agriculture techniques. Furthermore, marketing and alternate limitations, pest and livestock problems, lack of credit availability in agriculture production and lack of agriculture specific financing are also the major factors behind low productivity (Pakistan economic survey).

The remaining part of the paper organized as follows; section- II review some relevant literature of agricultural sector and government expenditure. Section- III represents the data resources, empirical model and methodology used in the study. Section- IV provides empirical results followed by final section $V$ which provide us the appropriate conclusion from the study and gives policy recommendation.

\section{LITERATURE REVIEW}

The relationship between government spending on agriculture, agriculture product prices and economic growth has been considerably treated inside the hypothetical and experiential literature. The theoretical basis of this relationship can be followed as back as the time of Keynes (1936). The schools of thought emerged on the course of connection among agricultural product prices, expenditure of government and gross domestic product of agriculture. Keynes (1936) stated that government authority's uses government spending on agriculture as a tool to turn around the financial declines thorough spending money on numerous programs which they borrowed from private sector and thereafter returned that money to them which consequently brings financial development.

Gylfason et al. (2000) review the reasons involves in delaying economic progression regardless of abundance in natural resources and extensive agriculture in all over the world. It further incorporates observational and cross-sectional evidence of specific aspects in connection with transition of economies in Eastern, Central Europe and Central Asia since 1990. It was argued that heavy reliance on the natural assets and agriculture may result in pursuing corruption and policy failure. Moreover, it may also weaken education system, trade and genuine savings and thereafter slowing down the whole growth process in the economy.

Gollin et al. (2002) explore the version of structural transformation and argued that this theory was useful concept of each questions consist in it. Industrialization takes place at diverse circumstances but why it considered and advances slowly. It was further established that important reasons of low production in industries are low agriculture yield and their astonishing dependency on agriculture. Although, agriculture is very supportive to develop an industry in powerful way but in the event that execution of businesses goes downward it effects the economic growth negatively.

Chebbi (2010) wants to assess the function of agriculture along with other sectors in the economic growth. For that purpose Johansen's multivariate method has been utilized to gain knowledge of co integration and deeply measured the easy methods to overwhelm the spurious regression problem. Results demonstrated that all economic sectors co integrate and have a tendency to maneuver collectively. He also gave careful consideration to research non-casualty amongst agriculture and the opposite financial sectors. 
Nurudeen et al. (2010) tried to illustrate the relationship between government expenditure and economic growth of seven countries; France, United Kingdom, Germany, Japan, Italy, Canada and United State of America. They suggested significant fluctuation among government expenditure and economic growth over time. Their study indicates no strong progressive evidence of impact of government expenditure on economic growth. One is posited by Qazi at el. (2010) that both agricultural expenditure policy and pricing policy are essential for boosting up the economy but price policy have more influence on the agriculture sector.

Rosovsky (2011) examine the role of agriculture in the modern Japanese economic growth and highlighting that it turns into two fold problems. Firstly, summarizes the significance role and main features of agriculture on the economy. Secondly, during the growth process evaluating the relationship between agriculture and other sectors.

Ebere Chidinma at el. (2012) indicates that expenditure of government, output of agriculture and gross domestic product have positive relation and there exist significant relationship between government expenditure in agriculture and economic growth in Nigeria.

Alshahrani et al. (2014) demonstrated the impact of various classifications of Government consumption on rural and monetary development in Saudi Arabia. The study used time series data for the period of 1969-2010. Results show long run and short-run effects of growth utilizing diverse econometric schemes and instruments especially Vector Error Correction Model and stimulates the improvement in long-run.

\section{DATA SOURCES AND METHODOLOGY}

Data and variables. This study used three variables - gross domestic product of agriculture, government expenditure on agriculture and agriculture product prices for the period of 20 years from 1996-2015. Data obtained on agriculture GDP and government expenditure 1 in annual percentages from agriculture section of World Development Indicators (WDI). Agriculture product prices are the accumulation of maize and wheat. Data of prices were taken from Food and Agriculture Organization of the United Nations and based on producer price index $(2004-2006=100)$. Gross domestic product of agricultural sector is used as an indicator of agriculture performance.

Econometric model. The study specified the following equation to examine the effects of government expenditure and agriculture product prices on the agriculture economic growth of Pakistan. It is define as:

$$
\ln \left(A_{G t}\right)=\beta_{0}+\beta_{1} \ln \left(R M_{t}\right)+\beta_{2} \ln \left(F C_{t}\right)+\beta_{3} \ln \left(M_{t}\right)+\beta_{4} \ln \left(W_{t}\right)+U_{t}
$$

Where:

$A_{G t}=$ Performance of agriculture sector (Agricultural GDP);

$\mathrm{RM}_{\mathrm{t}}=$ Agriculture raw material imports;

$\mathrm{FC}_{\mathrm{t}}=$ Gross fixed capital form;

$\mathrm{M}_{\mathrm{t}}=$ Maize prices;

$\mathrm{W}_{\mathrm{t}}=$ Wheat prices;

$\mathrm{U}_{\mathrm{t}}=$ error terms.

The In represents natural logarithmic form of series while parameters $\beta_{1}, \beta_{2}, \beta_{3}$, and $\beta_{4}$ are the long-run elasticity's of $A_{G t}$ with respect to RM, FC, M and W respectively. Engle and Granger (1987) test, maximum likelihood-based Johansen $(1988,1991)$ and JohansenJuselius (1990) tests are the most widely used methods to investigate co integration (longrun equilibrium relationship) among variables. In these methods, all the variables incorporated in the model must be stationery at first difference. Another limitation of these methods is the poor performance in case of small sample size but to avoid these limitations, Autoregressive distributed lag (ARDL) approach of co integration was used. Pesaran, Shin and Smith (1996) and Pesaran and Shin (1999) developed this approach whereas Pesaran

${ }^{1}$ Agriculture raw material (\% of merchandise imports) and gross fixed capital form (\% of GDP). 
et al. (2001) developed it further. This method of co integration has various econometric advantages over other methods, hence gained wide acceptance. This approach is different from the other approaches, does not oblige all the variables to be integrated of the same order i.e. I (1). This approach is equally good if all variables in a model are I (0) or I (1) or even fractionally integrated (Pesaran and Pesaran, 1997). Pesaran and Shin (1999) argued that ARDL approach of co integration provides stout results and super consistent estimates of the long-run coefficients in case of small samples. Considering above advantages of ARDL approach of co integration, we specify the following model:

$$
\begin{gathered}
\ln (A G t)=\beta_{0} \sum_{i=1}^{q} \beta_{1 i} \ln (A G t-i)+\sum_{i=0}^{q} \beta_{2 i} \ln (R M t-i)+\sum_{i=0}^{q} \beta_{3 i} \ln (F C t-i)+\sum_{i=0}^{q} \beta_{4 i} \ln (M t-i) \\
\quad+\sum_{\substack{i=0 \\
\text { in }}}^{q} \beta_{5 i} \ln (W t-i)+\beta_{6} \ln (A G t-1)+\beta_{7} \ln (R M t-1)+ \\
\beta_{8} \ln (F C t-1)+\beta_{9} \ln (M t-1)+\beta_{10} \ln (W t-1)+U t
\end{gathered}
$$

Where: $q$ is the optimal lag length, $\beta_{1}, \beta_{2}, \beta_{3}, \beta_{4}$, and $\beta_{5}$ represents short-term dynamic and $\beta_{6}, \beta_{7}, \beta_{8}, \beta_{9}$ and $\beta_{10}$ are the long run elasticity's of the model. Before running the ARDL model we tested the level of integration of all variables because if any variable is I (2) or above ARDL approach is not applicable. For this we use Augmented Dickey-Fuller (ADF) and Phillips-Perron test. To find out the long-term relationship as given in equation (1), we conducted bounds test of equation (2) using F-statistic with 2 boundaries, i.e. lower bound and upper boundaries. The null hypothesis assumes no co integration among variables. If the value of F-statistic is greater than the upper bound value then the null hypothesis is rejected and if it is less than the lower bound then null hypothesis is accepted and if it falls between the lower and upper bounds the test is inconclusive. After testing co integration we use Schwarz Bayesian Criterion (SBC) to select the optimal lag length of variables.

\section{RESULTS AND DISCUSSION}

Before applying ARDL approach of co integration, unit root test was applied to check whether all variables are stationery or not. Table 1 presents the results of Augmented Dickey Fuller Test Statistic and Phillips-Perron Test Statistic at level and at first difference. According to results, all the variables were stationery at first difference form at one percent significance level in both tests. In this situation we can apply ARDL approach of co integration.

Table 1 - Unit Root Test Results

\begin{tabular}{ccccc}
\hline Variables & $\begin{array}{c}\text { Augmented Dickey } \\
\text { Fuller Test Statistic (At Level) }\end{array}$ & $\begin{array}{c}\text { Augmented Dickey } \\
\text { Fuller Test Statistic } \\
(1 \text { st Difference) }\end{array}$ & $\begin{array}{c}\text { Phillips-Perron } \\
\text { Test Statistic (At Level) }\end{array}$ & $\begin{array}{c}\text { Phillips-Perron } \\
\text { Test Statistic } \\
\left(1^{\text {st }} \text { Difference) }\right.\end{array}$ \\
\hline $\ln \mathrm{A}_{\mathrm{Gt}}$ & -1.304144 & $-3.690331^{*}$ & -1.400203 & $-3.690331^{*}$ \\
In $\mathrm{RM}_{\mathrm{t}}$ & $-4.453027^{*}$ & $-3.937954^{*}$ & $-5.036410^{*}$ & $-10.30722^{*}$ \\
$\ln \mathrm{FC} t$ & -1.617300 & $-3.611027^{*}$ & -1.744731 & $-3.581908^{*}$ \\
$\ln \mathrm{M}_{\mathrm{t}}$ & 0.516925 & $-4.058164^{*}$ & 0.586261 & $-4.072545^{*}$ \\
$\ln \mathrm{W}_{\mathrm{t}}$ & -0.124000 & $-4.564907^{*}$ & -0.124000 & $-4.564907^{*}$ \\
\hline
\end{tabular}

* show significance level at 1 percent.

Source: Author's own calculation using E views 9.

Results of long-run relationship are keen to lag-length selected in the model (BahmaniOskooee and Bohal, 2000). Table 2 present the computed F-statistic to choose optimal laglength in the model. According to Pesaran et al. (2001) with lag of order 3 the lower and higher bound values at 95 percent significance level are 2.86 and 4.01 correspondingly. The critical value bounds are computed by stochastic simulations using 20000 replications. Table 2 shows that the computed value of F-statistic (4.16) is greater than the upper bound 
value of F-statistic which help us to reject the null hypothesis of long run relationship. As a result, there exists long-run relation between the variables.

Table 2 - F-Statistics for Testing the Existence of Long-Run Relationship

\begin{tabular}{ll}
\hline Order of Lag & F-Statistic \\
\hline 1 & 4.16 \\
\hline
\end{tabular}

The lower and upper bound values (2.86 and 4.01 at 95 percent) for F-statistic are taken from Case III: unhampered intercept and no trend given in Pesaran et al. (2001). We used Schwarz Bayesian Criterion (SBC) to select the optimal lag length of variables incorporated in the ARDL model. Table 3 presents the results of long-run relationship of the chosen ARDL model $(1,1,1,0,0)$ using SBC.

Table 3 - Long-Run Coefficients of ARDL (1, 1, 1, 0, 0) Model Dependent Variable GDP

\begin{tabular}{llll}
\hline Regressor & Coefficient & Standard Error & T-Ratio \\
\hline In $\mathrm{RM}_{\mathrm{t}}$ & 0.81 & 0.12 & $6.59^{*}$ \\
In $\mathrm{FC}_{\mathrm{t}}$ & 0.37 & 0.14 & $2.63^{*}$ \\
In $\mathrm{M}_{\mathrm{t}}$ & 0.38 & 0.09 & $4.22^{*}$ \\
In $\mathrm{W}_{\mathrm{t}}$ & 0.32 & 0.07 & $4.70^{*}$ \\
$\mathrm{C}$ & 0.64 & 0.24 & $2.63^{*}$ \\
\hline
\end{tabular}

* show significance level at 1 percent.

$R^{2} \quad .957$

Adj. $R^{2} \quad .927$

$F(6,14) \quad 31.84$

Prob. (F-stat) 0.000

D.W. $\quad 2.891$

Table 3 reveals that in the long run prices of agriculture products and expenditure of government on agriculture have statistically significant positive impact on the agricultural performance. But agricultural expenditure has greater influence on agriculture sector. The coefficients of RMt, FCt, Mt and W shows that one percent increase will bring $0.81,0.37$, 0.38 and 0.32 percent positive change in the agriculture economy of Pakistan respectively. Values of $R^{2}$ and adjusted $R^{2}$ describe that the model is best fit. F-statistics is significant and Durbin-Watson criteria are also fulfilled as the value is more than two.

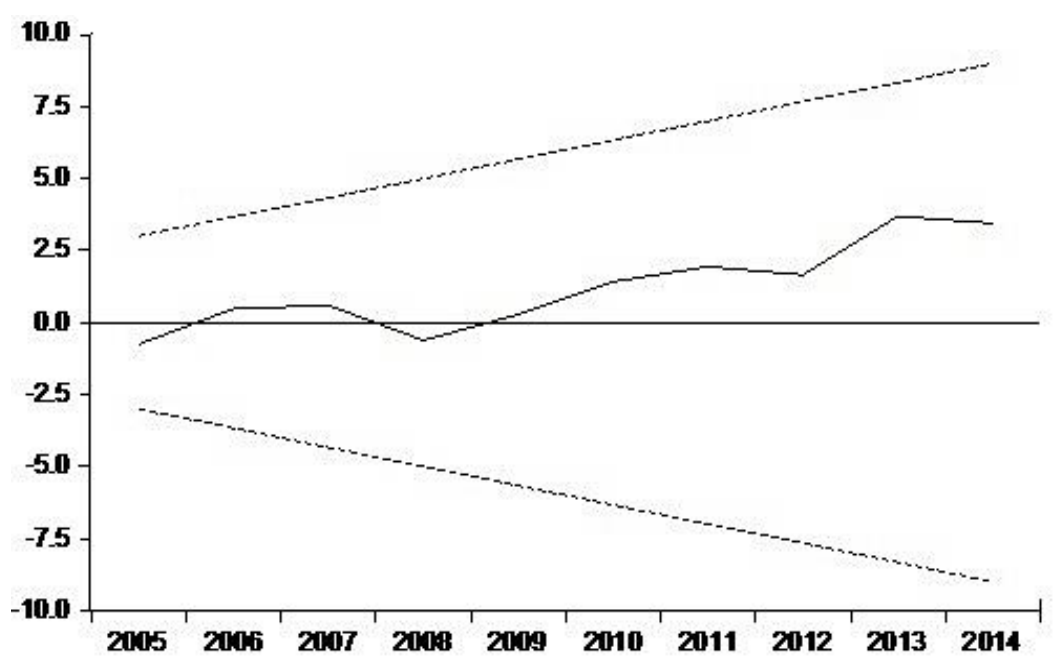

The straight line represents critical bounds at 5\% significance level.

Figure 1 - Plot of Cumulative Sum of Recursive Residuals 


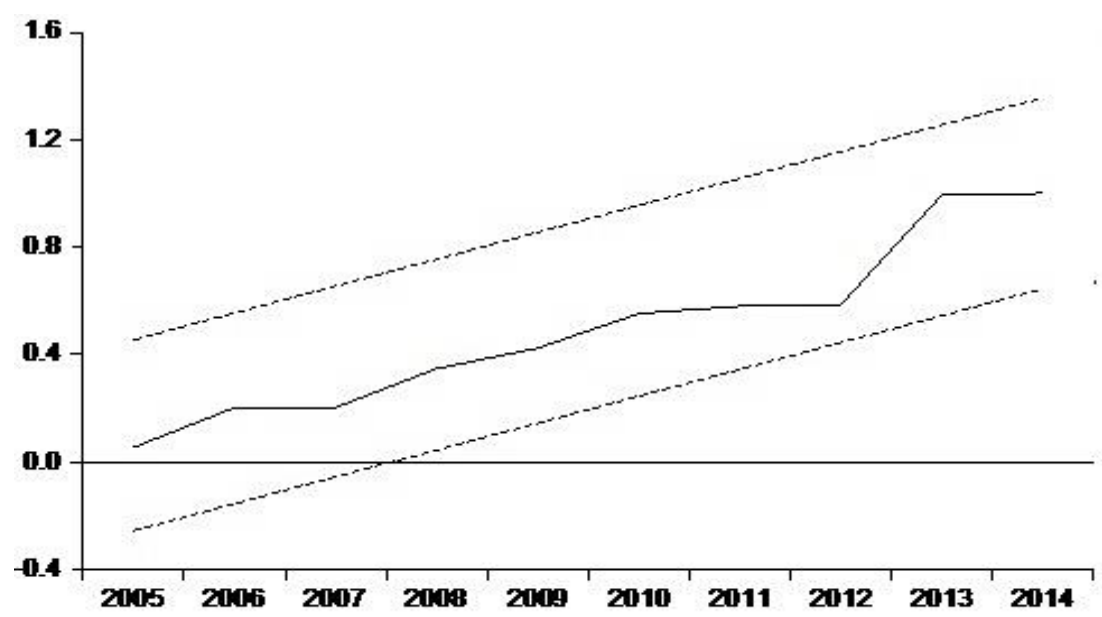

The straight line represents critical bounds at 5\% significance level.

Figure 2 - Plot of Cumulative Sum of Squares of Recursive Residuals

We tested the stability of the selected ARDL model using cumulative sum of recursive residuals (CUSUM) and cumulative sum of squares of recursive residuals (CUSUMSQ) stability testing technique presented by Brown et al. (1975). CUSUM and CUSUMSQ plots have been shown in Figures 1 and 2 respectively. Since both the plots remain within critical bounds at 5 percent level of significance, we conclude that the model is structurally stable.

\section{CONCLUSION}

The study aims to investigate the relationships between government expenditure on agriculture, agriculture product prices and performance of agriculture sector. The variables used in this case were gross domestic product of agriculture, agriculture raw material imports, gross fixed capital, maize and wheat for the period of 1996-2015. The study employed autoregressive distributed lag approach of co integration for statistical implication due to several advantages. Empirical results indicate that there exists long-run relationship between the variables. Agricultural government expenditure is more prominent in effecting the agriculture economic growth with respect to agricultural products prices in the long-run. Although, all variables in the model have statistically positively influence but expenditures have greater impact on the growth. Furthermore, results presented in this study signify the importance of agriculture sector in the economy and also illustrate that both expenditure of government on agriculture and prices of agriculture products are essential for enhancing agriculture performance in the country. It also specifies that government of Pakistan should take initiatives to increase the percentage of government expenditure in shape of subsidies and different other measures to enhance the productivity in the economy.

Fund project: The Soft Science Project of Heilongjiang (GC13D409), Philosophy and Social Sciences Project of Heilongjiang (15JYE07).

\section{REFERENCES}

1. Alshahrani, M.S.A. and M.A.J. Alsadiq, "Economic growth and government spending in Saudi Arabia: An empirical investigation." International Monetary Fund (2014).

2. Altaf, Z. "Food security in pluralistic Pakistan." HUNGER (2009).

3. Bahmani-Oskooee, Mohsen, and Martin T. Bohl. "German monetary unification and the stability of the German M3 money demand function." Economics Letters 66.2 (2000): 203-208.

4. Chebbi,E.H, "Agriculture and economic growth in Tunisia." Emerald Group Publishing Limited 2 (2010): 63-78. 
5. Chang, Tsai-Yu. "The influence of agricultural policies on agriculture structure adjustment in Taiwan: An analysis of off-farm labor movement." China Agricultural Economic Review 3.1 (2011): 67-79.

6. Engle, Robert F., and Clive WJ Granger. "Co-integration and error correction: representation, estimation, and testing." Econometrica: journal of the Econometric Society 55 (1987): 251-276.

7. Ebere, Chidinma, Osundina, Kemisola C, "Government Expenditure on Agriculture and Economic Growth in Nigeria" International Journal of Science and Research 3 (2014): 188-194

8. Gylfason, T. "Resources, Agriculture, and Economic Growth in Economies in Transition Munich." cesifo working paper series 313 (2000): 13-15.

9. Gollin, Douglas, Stephen Parente, and Richard Rogerson. "The role of agriculture in development." The American Economic Review 92.2 (2002): 160-164.

10. Government of Pakistan, "Agricultural Statistics of Pakistan and Statistical Supplement." Islamabad: Ministry of Food, Agriculture and Livestock (2010).

11. GoP, "Economic Survey of Pakistan." Ministry of Finance, Government of Pakistan, Islamabad (2015).

12. Government of Pakistan, "Pakistan Bureau of Statistics." Agriculture Statistics (2015).

13. Hsieh,E. and K.S. Lai, "Government Spending and Economic Growth: The G-7 Experience." Journal of Applied Economics 26 (1994): 535-542.

14. Johansen, S. and K. Juselius, "Maximum likelihood Estimation and Inference on Cointegration with Applications on the Demand for Money." Oxford Bulletin of Economics and Statistics 52 (1990): 169-210.

15. Muhammad llyas, Hafiz Khalil Ahmad Muhammad Afzal and Tahir Mahmood, "Determinants of Manufacturing Value Added in Pakistan: an application of bounds testing approach to co integration." Pakistan Economic and Social Review 48(2010): 209223.

16. Nurudeen, Abu, and Abdullahi Usman. "Government expenditure and economic growth in Nigeria, 1970-2008: A disaggregated analysis." Business and Economics Journal 2010 (2010): 1-11.

17. Pesaran, M. Hashem, and Yongcheol Shin. "Cointegration and speed of convergence to equilibrium." Journal of econometrics 71.1 (1996): 117-143.

18. Pesaran, M. Hashem, and Yongcheol Shin. "An autoregressive distributed-lag modelling approach to cointegration analysis." Econometric Society Monographs 31(1998): 371413.

19. Pakistan, "Pakistan Economic Survey." Finance Division, Economic Advisor's Wing, Islamabad (2015).

20. Pesaran, M.H., Y Shin and R.J. Smith, "Bounds testing approaches to the analysis of level relationships." Journal of Applied Economics 16 (2001): 289-326.

21. Qazi Muhammad Adnan Hye, Summaira Malik and Masood Mashkoor, "Government Expenditure, Agricultural Product Prices and Agricultural Growth: A Case of Pakistan" Middle Eastern Finance and Economics 7 (2010): 56-62

22. Syed Ali Raza, Mr, Yasir Ali, and Farhan Mehboob. "Role of agriculture in economic growth of Pakistan." International Research Journal of Finance and Economics 83 (2012): 81-86. 